\title{
Self-Regulatory Behavior of Adolescent Students in Ethiopia -The Case of Ayer Tena High School, Kolfe Keranio Sub City, Addis Ababa, Ethiopia
}

\author{
Belay Tefera $^{1^{\star}}$, Abdinasir Ahemed ${ }^{2}$ and Mintesenot Fentahun ${ }^{3}$ \\ ${ }^{1}$ School of Psychology, Addis Ababa University, P.O. Box: 33617, Addis Ababa, Ethiopia \\ ${ }^{2}$ Jijiga Univerity, P.O. Box: 1020, Jigjiga, Ethiopia \\ ${ }^{3}$ Ayer Tena High School, P.O. Box: 70044, Kolfe Keranio Sub City, Addis Ababa, Ethiopia
}

\begin{tabular}{|c|c|}
\hline Abstract & Article Information \\
\hline \multirow{12}{*}{$\begin{array}{l}\text { Self-regulatory behavior is an important personal skill that strengthens in the course of } \\
\text { transition from childhood to adulthood. While self-regulation promotes healthy and successful } \\
\text { transitioning to adulthood, deficiency in self-regulation would expose the growing persons to a } \\
\text { host of undesirable behaviors including impulsivity, violence, health risky behaviors etc. The } \\
\text { aim of this study was to examine adolescents' self-regulatory behavior and how it was } \\
\text { associated with parental involvement and such other background factors as age, gender, } \\
\text { family structure, and socio-economic status. A total of } 211 \text { secondary school adolescent } \\
\text { students were selected as data sources. Socio-Economic Status Inventory, Self-Regulation } \\
\text { Scale and Parental Involvement Scale were employed for data collection. Findings indicated } \\
\text { that the level of self-regulatory behavior was significantly higher among the adolescents. The } \\
\text { same pattern was exhibited in all the three dimensions of self-regulation. While sex and } \\
\text { parental involvement were found to have significant relationship with self-regulatory behavior, } \\
\text { age, socio-economic status, fathers' educational level, and family structure were, however, } \\
\text { minimally correlated. Discussing the findings against a backdrop, basically of, socio-cultural } \\
\text { reality of the study setting, further research was suggested to unveil this context of self- } \\
\text { regulation using mixed research design. }\end{array}$} & Article History: \\
\hline & Received : 06-11-2014 \\
\hline & : 23-12-2014 \\
\hline & Accepted : 26-12-2014 \\
\hline & Keywords: \\
\hline & Self-regulation \\
\hline & Self-regulatory behavior \\
\hline & gulatory th \\
\hline & \\
\hline & \\
\hline & ${ }^{\star}$ Corresponding Author: \\
\hline & $\mathrm{Be}$ \\
\hline Cop & \\
\hline
\end{tabular}

\section{INTRODUCTION}

Adolescence is a stage in the life span that is socioculturally constructed (Elder, 1980; Kaplan, 2004), temporally, spatially and individually varied (Larson and Wilson, 2004; Nsamenang, 2004), and, hence, characteristically diverse (Degner, 2006). However, it is commonly designated as the period of life between childhood and adulthood (Brown et al., 2004; Kaplan, 2004), a "time of growing up, of moving from the immaturity of childhood into the maturity of adulthood (Steinberg, 2002), a period of preparation for the future (Steinberg, 2002), and a phase of life beginning in biology (with the initiation of pubertal changes) and ending in society (Petersen, 1988)with ages ranging from around ten and ending in early twenties (Steinberg (2002).It is a period of teenage years (from 13 to 19) (Degner, 2006) that corresponds with "the second decade of life" (Steinberg, 1999) in which most of a person's biological, cognitive, psychological, and social characteristics are changing in an interrelated manner" (Lerner, 2009, p. 150). These changes are characteristically so fundamental (Steinberg, 1999) that they transform the growing person from what is considered childlike to what is considered adult-like" (Lerner, 2009).
One of the fundamental socio-cognitive changes that makes adolescence transition take a special developmental overtone is the emergence of abstract thinking (Piaget, 1972). This ability to think in abstract ways enables adolescents to begin to 'think about their own thinking'; a psychological construct that came to be known as 'secondary- order thinking' (Steinberg, 1989), 'implicit psychological theory' (Barenboim, 1981), 'metacognition' (Flavell, 1971), 'hyper cognition' (Demetriou, 1996), 'prescriptive thinking' (Kohelberg and Ullian, 1974), 'self-control, 'self-management', 'selfdiscipline'... (Gottfredson and Hirschi, 1990) or, preferably for our present purpose, 'self-regulation'. According to McClelland, Ponitz, Messersmith, and Tominey (2010), other common terms related to the study of self-regulation include effortful control and executive attention (rooted in developmental psychology, particularly in studies of temperament), ego control/resiliency (rooted in personality psychology), executive function (rooted in clinical and developmental neuropsychology), decision making (rooted in cognitive psychology), engagement (rooted in educational psychology), and motivation (rooted in educational psychology and personality psychology); to name just a few of the most relevant to this discussion. 


\section{Belay Tefera et al.,}

Self-regulation generally refers to a deliberate attempt to modulate, modify, or inhibit actions and reactions toward a more adaptive end (Barkley, 2004). It is an online positive executive functioning that directs, guides, and monitors activities of a person and unfolds itself through such behaviors as inhibition, future time orientation, consequential thinking, planning, initiation, and regulation of goal-directed behavior (Buckner et al., 2003). As an executive functioning of the self, it alters its own responses or inner states actively and intentionally (Gazzaniga, in Steinberg, 1993) and may be thought of as that part of the self which is ultimately responsible for the actions of the individual. Typically, this takes the form of overriding one response or behavior and replacing it with a less common but more desired response, making rational choices among alternative courses of actions, and planning for the time ahead.

Evidences indicate that young people who rated themselves and their parents as high in self-regulation skills showed lower levels of internalizing behavior problems (depression or anxiety) than peers low in these skills, that stressed youth high in impulsivity with poor selfregulation show higher externalizing behavior problems than those low in impulsivity, and that good self-regulation contributed to resilience (Buckner et al., 2003). Furthermore, teens with strong self-regulation skills that came from low-income families experienced satisfactory mental health and emotional well-being, even after researchers considered self-esteem and nonverbal intelligence (Buckner et al., 2003). According to Bandura and colleagues (2003), perceived self-efficacy to regulate positive and negative affect is related to teens' beliefs that they can manage academic, transgressive, and empathic aspects of their lives, and these forms of perceived selfefficacy is related in turn to lower levels of depression, delinquency, and antisocial behaviors.

Although humans have an impressive capacity for selfregulation, failures are common and people lose control of their behavior in a wide variety of circumstances. Such failures are impulsivity and numerous other poor psychological outcomes (Bandura et al., 2003; Buckner et al., 2003; Gottfredson and Hirschi, 1990; Hamid et al., 2006). An array of factors structure this psychological functioning including socio-economic and cultural (McLoyd, 1998; Elias, 2005), sub-cultural (Masten, 2004), familial (Naom in Dacey and ravers, 2002; Solomon, 2004; Adugna, 2005; Emana, 2005) and individual variables (Hamid, 2005; Katz, 1999).Evidences indicate that financial insecurity and educational in-advancement at some point hampers development of self-regulatory behavior (Field and Marie, 1993). Attachments to adults who monitor and support youth, relationships with peers who regulate others, bonding to socializing and community organizations, and opportunities for regulatory capacity building (Masten, 2004) are likely to promote self-regulation. Adolescents who are nested in intact family structures are also likely to develop self-regulation compared with those in non-intact families (Dawson in Papalia et al., 2004; Hetherington et al., 1998; Johnson, Hoffman and Gersteinin Papalia et al., 2004; Ellies, 2003; Walker and Henning, 1997). In functional terms, intact families are likely to promote self-regulation mainly because they are likely to put at the disposal of young person a conducive environment for involved parenting. Given the high value placed on the relevance and importance of parents in the life of children (Naom in
Sci. Technol. Arts Res. J., Oct-Dec 2014, 3(4): 172-178

Dacey and Travers, 2002; Solomon, 2004; Adugna, 2005; Emana, 2005), then parents who do not have enough time to involve in their children's staffs may result in low selfregulated behaviors (Gottfredson and Hirschi, 1990; Naom in Dacey and Travers, 2002; Solomon, 2004; Adugna, 2005; Emana, 2005; Rueter and Conger, 1995; Simons et al., 1992) and these would make adolescents become easy prey of peer pressure for high risk activities like premarital sex, drug consumption and fighting (Diclemente et al. in Papalia et al., 2004). As regards individual factors, evidences indicate that there are gender (Hamid, 2005), and age (Katz, 1999) differences in the development of self-regulatory behavior. In most research findings age is a significant factor in predicting the possible self-control choice (Morris et al., 2007; Gottfredson and Hirschi, 1990).

Previous studies on gender and self-regulation behavior were mixed; some noted differences lending support to females' superiority (Gottfredson and Hirschi, 1990) while others reporting insignificant differences (Tittle et al. in Papalia et al., 2004). In the same way, although the positive role of intact families may not be questioned, most findings regarding blended families are, however, mixed: some disclose the supportive role of nonbiological parents (Sharma, McGue, and Benson, 1996) while others demonstrate existence of an invisible turmoil among adolescents and non-biological parents (Hetherington et al.,1989; Park and Buriel, 1998; McDonald and DeMoriesin Papalia et al., 2004) including adolescents who live even with their grandparents (Hetheringston et al., 1998; Crowley in Papalia et al., 2004). In the same way, although parental involvement is shown to impact on self-regulation, some researchers rather look for what is beneath the surface suggesting that parenting style is most probably contributing in the prediction of self-regulation (Gottfredson and Hirschi, 1990).

Although socio-economic status was also found to be an important factor in self-regulation, there are mixed findings when it comes to specific patterns; while some indicate that higher SES is to promote lower selfregulation (Niaz et al., 2005); others indicate that adolescents who have grown up in low socio-economic status homes are found to be low self-regulated (Gottfredson and Hirschi, 1990; McLyold, 1998) and middle socio-economic parent adolescents have higher self-regulatory behavior. Even with respect to age, while it is expected that self-regulation is to undergo refinements with age, evidences indicate that late adolescents are rather the most uncontrolled age group (Gottfredson and Hirschi, 1990).

Along with the arguments so far, we may need to examine self-regulatory behavior of young people in Ethiopia and the associated factors. Different research investigations indicate that many adolescents in Ethiopia seem to engage in a host of risky behaviors that lead to sexual and reproductive health problems, HIV/AIDS, unplanned pregnancy, and abortion(in Belay and Missaye 2014). Review of literature also shows that disciplinary/ behavioral problems, drug abuse, psychosocial and social adjustment difficulties, and many others are common problems of adolescents in Ethiopia (Belay and Yekoyealem, 2014). Hence, there is a need to investigate if self-regulatory behavior can be lower among adolescent students in Addis Ababa, and if the associated factors 
(age, sex, parental income, family structure, and parental involvement) would operate in a similar way in the Ethiopian (Addis Ababa) context.

\section{MATERIALS AND METHODS}

Participants: The study was carried out in Ayer Tena High School, Kolfe Keranio Sub City, Addis Ababa, Ethiopia. This School was purposively selected for many reasons. First, one of the authors of this article works in this school as a counselor and this would facilitate data collection by removing the suspicious attitude generated when getting into a newer territory. Many people experience a feeling of mistrust when approached for data collection seemingly linking such endeavors with political ends. Second, this approach was found cost-effective in so far as the research was done with little budget allocated for it. Third, as a suburb government school, Ayer Tena appears to provide a good mix of students from varied familial backgrounds.

This School is composed of a total of 1235 (588 male and 642 female) Grade Nine and Ten students regularly attending their class at the time of data collection. There were 14 sections of students in the two grades (8sections of Grade Nine and 6 sections of Grade Ten) of which only 7 were randomly selected. Then, each section was stratified gender-wise and a total of 240 participants were randomly selected with equal proportion of the two sexes. Sample size was calculated using the number of factors and categories involved in a research such that a minimum of 10 observations is required for each category of a factor (Drapper and Smith in Belay, 2013). Accordingly, there are 2 categories of Factor 1 (gender) $X$ 2 categories of Factor 2 (age) X 2 categories of Factory 3 (parental income and education) and 3 categories of Factor 4 (parental involvement) with a minimum of 10 observations per category yielding a total of about 240 participants. In fact, data analysis was based on 211 participants who provided complete data.

Instruments: Data collection employed three widely used instruments: Socio-Economic Satus Inventory, Self Regulation Scale, and Parental Involvement Scale.

Socio-Economic Status Inventory: was taken from Nuredin (2006) with modification made to make the items fit to the economic terms and conditions of the research context. The adopted inventory constituted of four aspects of social and economic indices: Educational Status Index (ESI), House Index (HOI), Earning Index (EAI) and Major Property Index (MPI).
Self-Regulation Scale: A modified version of the Grasmic and colleagues' (1993) Self-Regulation Scale was employed to measure participants' self-regulatory behavior. The Scale comprised of 39 items that fall into three sub-scales: Self-Regulatory Thoughts (11 items), Self-Regulatory Feelings (13 items) and Self-Regulatory Actions (15 items). The items were of a Likert-type rating format with 3 scale points: agree (3), disagree (2) and not sure (1). This scale is the most widely used measure of self-regulation and has been established as valid and reliable across representative nations of each continent (Papalia et al., 2004). Relibility indices of the sub-scales and the total scale were all above a Cronbach Alpha of 0.81 .

Parental Involvement Scale: was adapted from previous works (Admasu, 2004; Nyarko, 2007).There are 19 items adapted from these sources. The items in this scale are designed on the basis of activities that can reflect parents' direct and indirect involvement in their children's schooling at home as well as at school. These activities are described as parental help, time management, resources for intellectual development, initiation and reward for better academic performance, support and supervision and reducing work load at home. As in Self-Regulation Scale, the items were of a Likert-type rating format with 3 scale points: agree (3), disagree (2) and not sure (1). The reliability of this scale was found to be a Cronbach Alpha of 0.76 .

\section{RESULTS}

We are to begin with a brief analysis of the background characteristics of the participants. This is followed by presentation of the findings regarding the level of self-regulatory behavior and its dimensions. Then, associated factors are to be examined. Finally, attempts are made to identify the most potent factors that make a significant independent contribution in predicting selfregulatory behavior.

Background of Participants: Table 1 presents the descriptive statistical summary of the background characteristics of participants. As it can be noted in this table, about $48 \%$ are boys and the mean age of participants is 17 years. As regards family background, 82 $\%$ are from intact family; paternal education is, on the average, between secondary and (one year) post secondary education; and the average monthly income of both parents is Birr 2,117. 00.

Table 1: Descriptive summary of the variables $(\mathrm{N}=211)$

\begin{tabular}{|c|c|c|c|c|}
\hline Variables & Minimum & Maximum & Mean & SD \\
\hline Age & 14 & 20 & 17.00 & 0.404 \\
\hline $\operatorname{Sex}(=1$, if male $=0$, if female $)$ & 0 & 1 & 0.479 & 0.499 \\
\hline $\begin{array}{l}\text { Paternal educational status } \\
(0=\text { illiterate, } 1=\text { primary, } 2=\text { high school, } 3=\text { certificate } 4=\text { diploma } \\
\text { and } 5=\text { degree and above })\end{array}$ & 0 & 5 & 2.34 & 0.26 \\
\hline Family structure $(=1$, if intact $=0$, if non- intact $)$ & 0 & 1 & 0.82 & 0.384 \\
\hline Parental monthly income in Birr, SES & $<500$ & $>5000$ & 2117 & 92.25 \\
\hline
\end{tabular}

Self-regulatory Behavior: One sample mean test was conducted to determine the level of self-regulatory behavior among participants. The summary test statistic on Table 2 shows that the participants have significantly higher level of self-regulatory behavior ( $t_{210}=174.2$, $P<0.000$ ). The test statistics summarized in the same table also yielded that there is a significantly higher level of perceived parental involvement $\left(\mathrm{t}_{210}=174.2, P<0.000\right)$. 
Table 2: One sample t-test of the self-regulatory behavior and paternal involvement scores $(\mathrm{N}=211)$

\begin{tabular}{cccccccccc}
\hline Variables & $\begin{array}{c}\text { No. } \\
\text { of items }\end{array}$ & $\begin{array}{c}\text { Rating scale } \\
\text { points }\end{array}$ & $\begin{array}{c}\text { Expected } \\
\text { Mean }\end{array}$ & Min. & Max. & Mean & SD & t- value & Sig. \\
\hline Parental involvement & 20 & 3-points scale & 40 & 24 & 74 & 49.5 & 7.81 & 17.81 & 0.00 \\
\hline Self-regulation Total & 39 & 3-points scale & 78 & 63 & 112 & 95.5 & 7.95 & 174.2 & 0.00 \\
\hline
\end{tabular}

Dimensions of Self-regulatory Behavior: Selfregulatory behavior was defined in terms of three important constructs as in many other psychological variables (thoughts, feelings, and actions). The descriptive statistics and one-sample mean test results are summarized in Table 3. Referring to this table, we can observe that all the dimensions are significantly higher than the respective expected means: self-regulatory thoughts $\left(\mathrm{t}_{210}=149.33, P<0.000\right)$, self-regulatory feelings $\left(\mathrm{t}_{210}=126.9, \quad P<0.000\right)$, and self-regulatory behaviors $\left(\mathrm{t}_{210}=118.57, P<0.000\right)$.

Table 3: One sample t-test result on the dimension of self-regulation behavior among adolescents

\begin{tabular}{lccccccccc}
\hline $\begin{array}{c}\text { Dimension of } \\
\text { self-regulation }\end{array}$ & $\begin{array}{c}\text { Number of } \\
\text { items }\end{array}$ & $\begin{array}{c}\text { Expected } \\
\text { mean }\end{array}$ & Min. & Max. & Mean & SD & t- value & Sig. \\
\hline Self-regulatory thoughts & 11 & 22 & 20 & 33 & 28.02 & 2.725 & 149.33 & 0.000 \\
Self-regulatory feelings & 13 & 26 & 22 & 39 & 32.2 & 3.67 & 126.90 & 0.000 \\
Self-regulatory actions & 15 & 30 & 19 & 45 & 35.36 & 4.33 & 118.57 & 0.000 \\
\hline
\end{tabular}

Associated Factors: We may need to explain what possible factors are associated with self-regulatory behavior. Table 4 presents the correlation of some of the selected factors with self-regulatory behavior. Note in this table that it is only gender $\left(r_{210}=-0.17, P<0.05\right)$ and paternal involvement $\left(r_{210}=0.15, P<.05\right)$ that appear to have significant correlation with self-regulatory behavior. That is, girls (represented by ' 0 ') are significantly better in self-regulatory behavior than boys. And higher parental involvement is accompanied with higher self-regulatory behavior.

Table 4: Inter-correlation among variables of interests

\begin{tabular}{|c|c|c|c|c|c|c|}
\hline & 1 & 2 & 3 & 4 & 5 & 6 \\
\hline $\operatorname{Sex}(=1$, if male $=0$, if female $)(1)$ & 1 & & & & & \\
\hline Age (2) & 0.037 & 1 & & & & \\
\hline Family structure $(=1$, if intact $=0$, if non- intact) (3) & -0.09 & 0.16 & 1 & & & \\
\hline Socio-economic status (4) & 0.20 & 0.06 & 0.06 & 1 & & \\
\hline Educational status (5) & -0.02 & 0.11 & 0.03 & 0.40 & 1 & \\
\hline Parental involvement (6) & -0.18 & -0.05 & $0.23^{* *}$ & $0.14^{*}$ & 0.09 & 1 \\
\hline Self-regulatory behavior (7) & -0.17 & 0.01 & -0.01 & 0.05 & 0.05 & 0.15 \\
\hline${ }^{*} P<.05$ & & & $<.01$ & & & \\
\hline
\end{tabular}

Prediction of Self-regulatory Behavior: Multiple regression was conducted to determine the combined effects of all the predictor variables on self-regulatory behavior. It was found that about $3.1 \%$ (Multiple
$\left.R^{2}=0.031\right)$ of the variance in self-regulatory behavior is explained by all the predictors together. In fact, the test of beta weights indicates that it is only sex that makes a significant contribution $\left(\mathrm{t}_{210}=-2.436, P<0.016\right)$.

Table 5: Multiple regression analysis

\begin{tabular}{cccccc}
\hline Variables & Regression coefficient & Standard Error & Beta coefficient & t- value & Sig \\
\hline Sex & -2.748 & 1.128 & -.173 & -2.436 & .016 \\
Age & -.067 & 1.367 & -.003 & -.049 & .961 \\
family structure & .224 & 1.477 & .011 & .152 & .879 \\
Parental involvement & .132 & .073 & .130 & 1.803 & .073 \\
Socioeconomic status & -.367 & .215 & -.130 & -1.710 & .089 \\
Education status & .029 & .027 & .082 & 1.100 & .272 \\
\hline
\end{tabular}

This could be because of the overlaps among predictor variables. Hence, attempts are made to partial out overlaps among predictor variables to determine their net effect. The forward step wise variant of regression analysis is conducted for this purpose. First entry in the model goes to 'Sex'; accounting about $3 \%$ of the variance in self-regulatory behavior. No other variable could enter in the second step. The correlation between sex and paternal involvement was so strong that entry of sex in the model in step one nullified the role of paternal involvement.

\section{DISCUSSION}

This research was aimed at examining the level, dimensions and associated factors of self-regulatory behavior among adolescent students in Addis Ababa. The 


\section{Belay Tefera et alo,}

average age of participants (17 years) was found to place them into the stage, middle adolescence (15-18 years) (Lipsitzin steinberg,1999; Kagan and Coles in Steinberg, 1999), that corresponds with educational institutions' approximate age of high school (Steinberg (1999). Of course, this is a period of numerous changes (including self-regulation) that eventually transform the person from childlike to an adult like person. Masten argues that selfregulatory skills are needed to develop particularly at this stage in order to promote handling the various rapid changes and impulses of teens in making decisions about driving, sexual intimacy, or using drugs to cope with stress (Masten, 2004).

The findings of the present research indicate the existence of a higher level of overall self-regulatory behavior as well as its three dimensions (self-regulatory thoughts, feelings, and actions) mainly stimulated, among others, by socio-cultural factors and parenting practices in Africa in general and Ethiopia in particular. Cultural practices, proverbs, values and norms in Africa tend to promote responsible intelligence (Nsamenang, 1992), emotional, interpersonal, or social intelligence (Super and Harkness, 2008). Major goals of childrearing are centered more on such communal, social, spiritual and human values as belief in supernatural power, pro-social, caring and altruistic attitudes; cooperation and interdependence; self-restraint, unhurriedness and patience; responsibility for others; respect, loyalty and obedience to authority; and hard work, (Belay, 2011) rather than on such individualistic values as competitiveness, winning, achievement, success, independence, self-actualization, justice (Belay and Dawit, 2014). These social skills and humanistic values enable the person prioritize group interests over personal ones or suppress one' own requirements and consider the needs of others in the ingroup and children are "better together" within the free spirit and self-regulation; inter-stimulating and mentoring each other (Nsamenang, 1992) even when direct parental care and intervention is no longer available. The community parenting of African children (Belay, 2011), better expressed in the proverb "it takes a village to raise a child" (Sachs, 2008 in Time magazine), family members are not the only people to guide and supervise adolescents but almost the whole villagers are responsible in developing/inculcating the social norms and checking in adolescents anytime they get off track.

Generally, these experiences would develop selfregulation skill that allows making plans, choose from alternatives, control impulses, inhibit unwanted thoughts, regulate social behavior and live cooperatively. Those who are better able to self-regulate demonstrate improved relationships, increased job success, better mental health and are less at risk of developing alcohol abuse problems, engaging in risky sexual behavior and high school performance (Gottfredson and Hirschi, 1990; Hamid et al., 2006).

If self-regulation assumes these and related other important contributions in the development of young persons, then adolescents in Addis Ababa are supposed to retain smooth transitioning into adulthood. However, evidences seem to portray otherwise (Belay and Missaye, 2014; Belay and Yekoyealem, 2014; Belay and Sintayehu, 2008; CAYAO, 1995; Deme, 1997; Mulunesh, 2005; YNAT, 2004; Yusuf, 1998). Mulunesh (2005) reported that over $52.3 \%$ of adolescence in Gondar had experienced
Sci. Technol. Arts Res. J., Oct-Dec 2014, 3(4): 172-178

unpleasant emotional situations and more than $56 \%$ had reported of facing negative relationships with their parents'. As to Yusuf (1998) and Deme (1997), Ethiopian high school students (adolescents) are the most neglected and least understood age group, so they are at risk everywhere. According to Youth Net Assessment Team (YNAT, 2004), a good proportion of Ethiopian adolescents are highly involved in risk taking behaviors like unsafe sex, drug abuse, alcoholism, delinquency, etc. (see also CAYAO, 1995; Yusuf, 1998; FDRE-MOH, 2002).

Greater risk in the face of self-regulatory behavior is an apparent contradiction. This contradiction can be explained from different perspectives. Adolescents' increased facility in perspective taking dictating them to present themselves in favorable light while responding to the items of the questionnaire could be one. Normalizing the abnormal as a cultural script for adolescents to write up their identity could be another. Smoking, drugs, early sex and others may constitute the sub culture along which todays' adolescents are expected to socialize themselves with as a normal part of growing up into adulthood. Practicing alcohol begins in early childhood with local drinks ('tela', 'arekie', 'tej') at the homestead in many families in Ethiopia. Taking a drug ('chat') is also culturally accepted in many parts of Ethiopia. Violence as a method of conflict resolution, and particularly gender-based violence, is again not only culturally tolerated but also encouraged to prove manhood; despite massive gender awareness creation movements in Ethiopia. Violence at school is then an extension rather than exception of all these cultural practices and social rules.

The socio-cultural issues would also make sense explaining the other interesting finding of this research about associated factors; that many of the variables shown to have significant explanatory contribution to selfregulatory behavior (i.e. age, socio-economic status, and family structure) in previous research were not found to retain this position in the present research. That is, selfregulatory behavior is affected by general societal belief and, practices rather than specific individual developmental experiences. In fact, restriction of range would somehow limit the role of these variables as well.

In fact, gender was found to make significant difference in self-regulation; supporting previous studies showing females being more self-regulated than males (Gottfredson and Hirschi, 1990). The external control, supervision and monitoring that girls experience would gradually enable them to translate this external scripts into an internal speech (Diaz and Berke, 1992). Parental involvement was in fact another important factor correlated with self-regulation as it was also noted in previous research (Adugna, 2005; Diclemente et al ...in Papalia, 2004; Emana, 2005; Gottfredson and Hirschi, 1990; Naomin Dacey and Travers, 2002; Rueter and Conger, 1995; Simons, 1992; Solomon, 2004) but because it was also strongly correlated with sex, its role was consumed when entered into the regression equation along with gender. That is, sex has parental involvement plus some more things in it. On the other hand, age, family structure, and socio-economic status were not significant possibly for the added reason that there could be restriction of range. The socio-economic status of parents in government schools in Ethiopia is largely lower and almost homogenous. The same restriction of 
Belay Tefera et al.,

variability is also evident in the age of respondents. Hence, widening the range would improve the role of predictors.

\section{CONCLUSIONS}

It can be generally conclude that secondary school adolescent students in Ayer Tena School have a higher level of self-regulatory behavior. This same pattern follows in all the three dimensions of self-regulation. Furthermore, it was noted that while sex and parental involvement were the only two factors that explain self-regulation, the other factors (age, socio-economic status, family structure, fathers' education) were not found to correlate with selfregulation significantly. Failure of self-regulation is generally an important cause of several contemporary societal problems-substance abuse, poverty, and sexual infidelity and STIs, reckless driving, violence and crime, and so on. Hence, it is still needed for schools, parents, communities, and governments to jointly work still to facilitate development of self-regulation further. It is also recommended that further research be carried out employing mixed research designs to thoroughly examine self-regulation (through qualitative techniques) and the associated factors using quantitative approaches that draw data from varied sources and samples including from private schools to introduce wider variability in sample characteristics.

\section{REFERENCES}

Adugna Bersissa (2005). The relationship between Adolescents perception of Parental Monitoring, Connectedness, and Communication and their Sexual Risk Taking Behavior: The case of Nekemte High school. Unpublished MA thesis. Addis Ababa University. Addis Ababa.

Amato, P.R. (1987). Family process in one Parent, Step parent, and Intact Families: The child's point of view. Journal of Marriage and the Family 49: 327-337.

Bandura, A., Caprara, G.V., Barbaranelli, C., Gerbino, M., and Pastorelli, C. (2003). Role of affective self regulatory efficacy in diverse spheres of psychosocial functioning. Child Development 74(3): 769-782.

Barnboim, C. (1981). The development of person perception in childhood and adolescence: from behavioral comparison to psychological constructs to psychological comparison. Child Development 52: 129-144.

Barkley, R. A. (2004). Attention-deficit/hyperactivity disorder and self-regulation: Taking an evolutionary perspective on executive functioning. In R. F. Baumeister and K. D. Vohs (Eds.), Handbook ofself-regulation: Research, theory, and applications (pp. 301-323).New York: Guilford Press.

Belay Tefera (2011). Parenting in Africa: Guidelines, documentation and reporting practices. A research report submitted to The African Child Policy Forum, Addis Ababa.

Belay Tefera and Dawit Solomon (2014.). Goals of child bearing, perception of a 'good child' and paternal involvement in childcare among Ethiopian fathers living in Addis Ababa and Nashville, USA. A research report submitted for publication, Addis Ababa University.

Belay Tefera and Missaye Mulatie (2014).Risky sexual behavior and identity construction among adolescents in Ethiopia. Journal of AIDS and HIV Research, 6(3), 65-71.

Belay Tefera and Sintayehu Tadesse. (2008). National framework of life skills training for young people in Ethiopia. Ministry of Youth, Culture and Sports, Addis Ababa
Sci. Technol. Arts Res. J., Oct-Dec 2014, 3(4): 172-178

Belay Tefera and Yekoyealem Dessie (2014.). Exploring youth development in Addis Ababa: A strength-based approach. A research report submitted for publication, Addis Ababa University.

Brown, B.B., Larson, R.W. and Sarawathi, T.S. (2004). (Eds.). The world's youth: Adolescence in eight regions of the globe. New York: Cambridge University Press.

Buckner, J. C., Mezzacappa, E., and Beardslee, W.R. (2003). Characteristics of resilient youth living in poverty: The role of self-regulatory processes. Development and Psychopathology 15: 139-162.

(CAYO) Children and Youth Affairs Organization. (1995) "Ethiopian Youth: Basic Challenges and Prospects" Mimogaraph, Addis Ababa.

Dacey, S.J and Travers, F.J. (2002). Human Development: Across Life Span ( $5^{\text {th }}$ ed.)Boston: McGraw Hill

Degner, A.J. (2006). The definition of adolescence: one term fails to adequately define this diverse time period. CHARIS: A Journal of Lutheran Scholarship, Thoughts, and Opinion 7-8

Deme Argachew (1997). The Relationship between Family Management Practices and Adolescents Problem Behaviors: The case of East Shoa high school. Unpublished MA thesis, Addis Ababa.

Demetriou, A., Kazi, S. Platsidou, K.S. Efklides, A. and Kiosseogliou (1996). Self-image and cognitive development: structure, development and functions of self-evaluation and self-presentation in adolescence. Aristotle University of Thessaloniki. Unpublished Research Report.

Diaz, R.M., and Berk, L.E. (1992). Private speech. From social inter action to self-regulation. Hillsdale, NJ: Erlbaum.

Elder, G.H. (1980). Adolescence in historical perspective. In: J. Adelson (Ed.), Handbook of Adolescent Psychology, 346. New York: Wiley

Elias Kassa (1999).The Relationship of Parenting Styles and Socio-economic Status with Juvenile Delinquency: with particular reference to the Addis Ababa Remand and Rehabilitation Home and in Bahir Dar. Unpublished MA Thesis, Addis Ababa University, Ethiopia.

Ellies, B., Bates, J., Dodge, K., Ferguson, D, Harwood, J., Petlit, G., and Woodward, L. (2003). Does Father Absence Place Daughters at Special Risk for Early Sexual Activity and Teenage Pregnancy? Child Development 74: 801-821.

Emana Tucho (2005). Responsibility Behavior among Adolescents as a Function of Parenting Styles: The case of Nedjo District. Unpublished MA thesis .Addis Ababa University. Addis Ababa

FDREMoH (2002). AIDS in Ethiopia (4th ed.), Addis Ababa, Ethiopia.

Field, B.D. and Maries, A.S. (1993). Self-control and Juvenile Delinquency: Theoretical Issues and Empirical assessment of selected elements of general Theory of crime. Deviant Behavior 14(3): 243-264.

Flavell, J.H. (1971). First discussants' comments: What is memory development? Human Development 14: 273278.

Goldberg, W. A., Green Berger, E. and Nagel, S.K. (1996). Employment and Achievement: Mothers work Involvement in Relation to Children's Achievement Behaviors and Mothers Parenting Behaviors. Child Development 67: 1512-1527.

Gottfredson, M. and Hirschi, T. (1990). A General Theory of Crime. Stanford, CA: Stanford University Press. 
Belay Tefera et al.,

Hamid, A., Alireza, H., Anousliravan, K., Froug, S.(2006). Status of Self-regulation and its Relation to Drug Abuse Related Behaviors among Iranian Male High School Students, the Social Behavioral and Personality.

Hetherington, E.M., Bridges, E.M., and Insabella, G.M (1998). What matters? What does not? Five Perspectives on the Association between Marital Transitions and Children's Adjustment. American Psychologist 53: 167184.

Heyns, B. and Catsambis, S. (1986). Mothers Employment and Children's Achievement: A critique. Sociology of Education 59: 140-151.

Kaplan, P.S. (2004). Adolescence. Boston: Houghton Mifflin Company

Katz, R.S. (1999).Building the Foundation for aside by side Explanatory Model: A General Theory of Crime, the age graded life-course Theory and Attachment Theory" Western Criminology Review.

Katzev, A.R., Warner, R.L and Acock, A.C. (1994). Girl or Boy? Relationship of Child Gender to Marital Instability. Journal of Marriage and the Family 56: 89-100.

Kohleber, L. and Ullian, D.Z. (1974). Stages in the development of psychological concepts and attitudes. In R.C. Friedman et al. (Eds.).Sex differences in behavior. Huntington: Robert F. Krieger Publishing Company.

Larson, R., and Wilson, S. (2004). Adolescence across place and time: Globalization and the changing pathways to adulthood. In: M.R. Lerner and L. Steinberg (Eds.). Handbook of Adolescent Psychology. 299-330 Hoboken, $\mathrm{NJ}$ : John Wiley and Sons, Inc

Lerner, R.M. (2009). The positive youth development perspective: Theoretical and empirical bases of a strengths-based approach to adolescent development. In C. R. Snyder, and S. J. Lopez (Eds.), Oxford handbook of positive psychology (pp. 149-164).Oxford University Press.

Martha Medhanie (2005). The Contribution of Perceived Parent-Adolescent Relationships to Autonomy Development and Psychological Adjustment of Adolescents. Unpublished MA Thesis .Addis Ababa University, Addis Ababa.

Masten, A.S. (2004). Regulatory processes, risk and resilience in adolescent development. Annals of the New York Academy of Sciences 1021: 310-319.

McClelland, M. M., Ponitz, C.C., Messersmith, E.E. and Tominey, S. (2010). Self-Regulation: Integration of Cognition and Emotion. In Overtone, W. F. and Learner, M. (Eds.), The Handbook of Life Span Development: Cognition, Biology, and Methods, Vol. 1, 509-553. John Wiley and Sons, Inc., Hoboken, New Jersey.

McLyod, V.C. (1998). Child Poverty. In Damon (Ed.). Hand book of child psychology (5th ed.vol.4).New York: Willey.

Mengesha Nigus (2013). The Relationship between Perceived Parental Involvement and Academic Achievement, Academic Motivation and academic Selfesteem of Secondary and Preparatory School Adolescents in Alamata Town. MA thesis, Addis Ababa.

Mulunesh Abebe (2005). Psychological Characteristics of Adolescents and its Implications for Risky Behaviors: A case of Gondar Town Secondary Schools. Unpublished MA thesis. Addis Ababa University. Addis Ababa.

Niaz, U., Siddiqui, S., Ahmed, S., and Akhter, R. (2005). A Survey of Psycho Social Correlates of Drug abuse in young Adults Aged $16-21$, in Karachi identifying 'High Risk' population to Target Interventions Strategies. Journal of Medical science 21(3): 271-277.
Sci. Technol. Arts Res. J., Oct-Dec 2014, 3(4): 172-178

Nsamenang, A.B. (1992). Human development in cultural context: A third world perspective. Newbury Park, California: SAGE.

Nyarko, K. (2007). Parental Involvement: A Sine Qua Non in Adolescents' Educational Achievement: Gana, LudwigMaximilian University

Nuredin Mohamed (2006). Self-esteem of Adolescents as related to Parenting style and Socio economic status of Parent's. Unpublished MA Thesis .Addis Ababa University, Addis Ababa.

Papalia, D.E., Olds, S.W. and Feld Man, R.D. (2004). A Child world: Infancy through Adolescence. Boston: McGraw Hill.

Park, R.D., and Burriel, R. (1998). Socialization in the Family: Ethnic and Ecological Perspectives. In W. Damon (series Ed.) and N. Eisenberg (Vol. Ed.), Hand Book of Child Psychology: Vol.3. Social, Emotional and Personality Development (5th ed., pp.463-552).New York: Wily.

Petersen, A.C. (1988). Adolescent development. In: M.R. Rosenzweig (Ed.). Annual Review of Psychology 39: 583607. Palo Alto, CA: Annual Reviews.

Piaget, J. (1972). Intellectual evolution from adolescence to adulthood. Human Development 15: 1-12.

Richardson, J.L., Radziszewska, B., Dent, C.W. and Flay, B.R. (1993). Relationship between after School Care of Adolescents and Substance use, Risk taking Depressed Mood and Academic Achievement. Peditrics 92:32-38.

Rueter, M.A. and Conger, R.D. (1995). Interaction Style, Problem Solving Behavior, and Family Problem Solving Effective. Child Development 66: 98-115.

Sharma, A.R., McGue, M.K., and Benson, P.L. (1996). The Emotional and Behavioral Adjustment of United States Adopted Adolescents, part II: Age at Adoption. Children and Youth Services Review 18: 101-114.

Simons, R.L., Lorenz, F.O., Conger, R.D., Wu, C.I. (1992). Support from Spouse as a Mediator and Moderator of the Disruptive Influence of Economic Strain on Parenting. Child Development 63: 1282-1301.

Solomon Shiferaw (2004). The Effect of Living Arrangements and Parental Attachment on Sexual Problems of Adolescents in Dessie Preparatory School, Ethiopia. Unpublished MA Thesis.Addis Ababa University, Addis Ababa.

Steinberg, L. (1986). Latchkey Children and Susceptibility to Peer Pressure: An Ecological Analysis. Developmental Psychology 22: 433-439.

Steinberg, L. (1989). Adolescence. New York: McGraw-Hill.

Steinberg, L.D. (1993). Adolescence. New York: McGraw Hill.

Steinberg, L. (2002). Adolescence. (6 $6^{\text {th }}$ ed.). New York: McGraw-Hill.

Super, C.M. and Harkness, S. (2008). Globalization and its discontents: challenges to developmental theory and practice in Africa. International Journal of Psychology 2: 103-113.

Walker, L.J and Henning, K.H. (1997).Parent Child Relationship in Single Parent Families. Condition Journal of Behavioral Science 29: 63-75.

(YNAT) Youth Net Assessment Team (2004). Assessment of Youth Reproductive Health Programs in Ethiopia.

Yusuf, O.A. (1998).Gender Sensitive Counseling Psychology: a Hand book for Ethiopia High School Counselors. Addis Ababa: Addis Ababa University Press. 